\title{
LA AUTONOMIA INDÍGENA EN TIEMPOS DE PANDEMIA. PANAMÁ, LA COMARCA DE GUNAYALA Y LA COVID-19
}

\section{INDIGENOUS AUTONOMY IN TIMES OF PANDEMIC. PANAMA, THE GUNAYALA REGION AND COVID-19}

\author{
MÒNICA MARTÍNEZ MAURI ${ }^{1}$ \\ Universitat de Barcelona \\ martinezmauri@ub.edu
}

Fecha de recepción: 16 de octubre de 2020 / Fecha de aceptación: 23 de noviembre de 2020

RESUMEN: En el marco de este dossier dedicado al análisis de las respuestas que están dando los pueblos indígenas, desde el ejercicio de su libre determinación, para sobrevivir a la pandemia, el presente artículo se centra en analizar la experiencia del pueblo guna de Panamá. En primer lugar, presenta las acciones que han tomado las autoridades gunas en el marco de los derechos colectivos que tienen por formar parte de una comarca indígena. A continuación, contextualiza -histórica y ontológicamente- las medidas de cierre y puesta en cuarentena de la comarca durante los primeros días de la pandemia. En tercer lugar, analiza el control territorial y la gestión de flujos migratorios entre la ciudad y las comunidades indígenas que ejercen tanto las instancias políticas comarcales como estatales en Gunayala. Por último, reflexiona sobre los límites de las políticas de reconocimiento y el valor de la interculturalidad en el Panamá de hoy.

RESUM: En el marc d'aquest dossier dedicat a l'anàlisi de les respostes que estan donant els pobles indígenes, des de l'exercici del seu lliure determinació,

\footnotetext{
${ }^{1}$ El presente texto se enmarca en el proyecto financiado por: Institut d'Estudis de l'Autogovern a través dels ajuts a la recerca sobre l'organització territorial del poder (convocatòria 2018). Projecte: "Autodeterminació i sobirania dels pobles indígenes: atles d'un estudi en perspectiva interdisciplinària i comparada."
} 
per sobreviure a la pandèmia, el present article es centra en analitzar l'experiència del poble guna de Panamà. En primer lloc, presenta les accions que han pres les autoritats gunas en el marc dels drets col-lectius que tenen per formar part d'una comarca indígena. A continuació, contextualitza -històricament i ontològicament- les mesures de tancament i quarantena de la comarca durant els primers dies de la pandèmia. En tercer lloc, analitza el control territorial i la gestió de fluxos migratoris entre la ciutat i les comunitats indígenes que exerceixen tant les instàncies polítiques comarcals com estatals a Gunayala. Finalment, reflexiona sobre els límits de les polítiques de reconeixement i el valor de la interculturalitat al Panamà d'avui.

ABSTRACT: In the context of this dossier dedicated to the analysis of the responses that indigenous peoples are giving, from the exercise of their selfdetermination, to survive the pandemic, this article focuses on analyzing the experience of the Guna people of Panama. First, it presents the actions carried out by the Guna authorities within the framework of the collective rights they have as part of an indigenous comarca. It then contextualizes -historically and ontologically- the measures taken to lock down the region and place it in quarantine during the first days of the pandemic. Thirdly, it analyzes the territorial control and management of migratory flows between the city and the indigenous communities exercised by both regional and state political authorities in Gunayala. Finally, it reflects on the limits of the policies of recognition and the value of interculturality in today's Panama.

PALABRAS CLAVE: Pandemia - Pueblos indígenas - Autonomía - Panamá Gunayala

PARAULES CLAU: Pandèmia - Pobles indígenes - Autonomía - Panamà Gunayala

KEY WORDS: Pandemic - Indigenous peoples - Autonomy - Panama Gunayala

SUMARIO: I. Introducción: Panamá, comarcas indígenas y Covid-19. II. La respuesta ante el choque inicial: cierre, aislamiento y control. III. Pensar la autonomía indígena en tiempos de excepcionalidad. IV. Conclusión: los límites de las políticas de reconocimiento, el valor de la interculturalidad 


\section{INTRODUCCIÓN: PANAMA, COMARCAS INDÍGENAS Y COVID-19}

Panamá aún y no contar con una constitución pluricultural y ser uno de los pocos países latinoamericanos que no ha ratificado el convenio 169 de la Organización Internacional del Trabajo, ha avalado desde la primera mitad del siglo XX la creación de comarcas indígenas para algunos de los pueblos indígenas que se encontraban en el interior de sus fronteras. En materia indígena, a nivel nacional el país también cuenta con leyes que reconocen tierras colectivas indígenas (Ley 72 de 2008), derechos de propiedad intelectual sobre conocimientos y creaciones indígenas (Ley 20 de 2000), mecanismos de consulta y consentimiento previo e informado a los pueblos indígenas en caso de desarrollar proyectos dentro de sus zonas o impulsar iniciativas legislativas relativas a sus pueblos (Ley 37 de 2016) y la protección de la medicina tradicional indígena (Ley 17 de 2016). Actualmente existen tres comarcas indígenas Guna Yala, Emberá y Ngöbe Buglé- con una categoría equivalente a la de provincia, lo que significa que además de su propio sistema de gobierno cuentan con un gobernador comarcal. A estas tres se suman dos comarcas más -las gunas de Madungandi y Wargandi- con categoría de corregimiento y una tercera -la Naso Tjér Ni- que opera bajo el sistema de "propiedad colectiva". Según el censo nacional del año $2010^{2}$, el $48 \%$ de la población indígena panameña reside en zonas comarcales, es decir, en terruños indígenas con organización política semiautónoma bajo la jurisdicción del Gobierno nacional (Herlihy, 1995: 88). La comarca es una entidad político-administrativa que depende, en última instancia, del Estado, quien puede imponer entidades político-administrativas que limiten el ejercicio efectivo de los derechos reconocidos o puede explotar los recursos naturales de los territorios indígenas apelando al interés público (Wickstrom, 2003: 45). Históricamente los gunas, a pesar de no ser la sociedad indígenas con más peso demográfico del país, han

2 Desgraciadamente no contamos con datos más recientes. El censo 2020 ha quedado suspendido con motivo de las medidas de prevención para luchar contra la Covid19. 
sido los que más autonomía han ganado: tres de las seis comarcas que existen en Panamá son territorios gunas.

La consolidación de regímenes territoriales autónomos indígenas en Panamá es un referente para muchos otros pueblos del mundo. Este tipo de sistemas, al igual que los existentes en Colombia, Panamá, y Nicaragua, se caracterizan por: 1) la transferencia de competencias en la toma de decisiones y administración a autoridades democráticamente electas; 2) el reconocimiento de estructuras políticas de autogobierno; y 3) la delimitación de un territorio donde se ejercen derechos colectivos sobre la tierra y los recursos naturales (Díaz Polanco, 1997; González, 2010; Martínez Mauri, 2011).

En marzo del presente año, los pueblos indígenas del mundo, amparados o no por regímenes autonómicos, se vieron afectados por la propagación del coronavirus. Las condiciones de vida de muchas personas indígenas residencias multigeneracionales, falta de acceso a medidas preventivas y a centros sanitarios- provocaron que la pandemia de Covid-19 tuviera un efecto desproporcionadamente devastador en algunas comunidades indígenas (Curtice y Choo, 2020).

El 5 de agosto de 2020, la Red Regional de Monitoreo de FILAC reportó la existencia de un total de 62,473 casos positivos de Covid-19 entre la población indígena de América Latina, considerando solo aquellos países en los que se habían podido obtener o proyectar datos ${ }^{3}$. En Panamá -uno de los 12 países del mundo con más fallecidos de Covid-19 por millón de habitantes ${ }^{4}-$, desde el inicio de la pandemia, se han reportado 113.342 casos, de los cuales 2.387 han tenido un desenlace fatal ${ }^{5}$. Aunque no es posible saber con exactitud cual ha sido la afectación del virus entre la población indígena del país, si se han detectado

3 Cf. FILAC y FIAY, 2020: 39 https://indigenascovid19.red/wpcontent/uploads/2020/09/FILAC FIAY tercer-informe-PI COVID19 final.pdf [última consulta, 14-10-2020]

4 Según los datos de la Universidad John Hopkins, con 596,4 fallecidos de Covid-19 (entre el 22 de enero y el 11 de octubre) por millón de habitantes, Panamá ocupa el puesto número 12 del rànking de países más afectados por la pandemia https://www.prensa.com/sociedad/data-studiocasos-de-coronavirus-covid-19-en-panama/ [última consulta, 14-10-2020]

5 Datos de la Universidad John Hopkins <https://coronavirus.jhu.edu/map.html> [última consulta, 2/10/2020] 
brotes en comunidades indígenas, tanto dentro como fuera de las comarcas. La mencionada Red de FILAC contabilizó 1112 casos positivos de Covid-19 en población indígena de Panamá (hasta el 5 de agosto de 2020). En Gunayala a finales del mes de septiembre las cifras que manejaban los centros de salud de la región apuntaban a un total de 857 contagios confirmados acumulados, 32 habrían fallecido de Covid-196.

Más allá de las cifras, siempre inciertas e inevitablemente imprecisas, este artículo se propone reflexionar sobre la gestión de la pandemia por parte de las autoridades indígenas de la comarca de Gunayala, y más concretamente sobre el margen de autonomía que el gobierno panameño ha estado dispuesto a reconocer a las comarcas en unos momentos en los que se han puesto de manifiesto las limitaciones de la cobertura estatal, sobre todo en el plano sanitario, educativo e infraestructural. Para ello, es oportuno empezar narrando la reacción inicial del Congreso General de Gunayala (CGG) -la máxima autoridad de la comarca- ante el anuncio de la pandemia por la Organización Mundial de la Salud (OMS), para continuar analizando las decisiones que ha ido tomando a lo largo de estos últimos siete meses.

\section{LA RESPUESTA ANTE EL CHOQUE INICIAL: CIERRE, AISLAMIENTO Y CONTROL}

El día 11 de marzo de 2020, cuando la Organización Mundial de la Salud (OMS) decretó la pandemia, las autoridades de la comarca de Gunayala, junta directiva de los congresos generales, tomaron las primeras medidas para frenar la propagación del coronavirus a su territorio. Emitieron un primer comunicado invitando a las instituciones de gobierno presentes en Gunayala -Ministerio de Salud, Servicio Nacional de Fronteras (SENAFRONT) y Servicio Naval Aéreo Naval (SENAN) - a sumar esfuerzos para proteger a la población de la comarca. En este primer momento suspendieron todas las actividades turísticas y deportivas e impidieron el ingreso de embarcaciones comerciales o turísticas colombianas. Aunque en todo Panamá tan solo se habían reportado unos 8 
enfermos por Covid-19 -solamente uno de ellos había fallecido- y no se había detectado ningún positivo en la comarca, los gunas ya empezaron a prepararse para lo peor.

Esta preparación tan precoz tiene mucho que ver con dos factores: por un lado, el papel que tuvieron las epidemias en la historia, tanto pasada como reciente, del pueblo guna y de la mayoría de sociedades indígenas del continente americano; por el otro, está íntimamente relacionada con la centralidad que ocupan las bonigan (enfermedades) en el sistema ontológico guna.

Con la conquista, en el siglo $\mathrm{XVI}$, las sociedades nativas del istmo centroamericano aprendieron muy rápidamente que las enfermedades desconocidas tenían nefastas consecuencias sobre las poblaciones inmunológicamente indefensas (Denevan, 1976; Crosby, 1976). A lo largo de los siglos muchos han sido los virus y bacterias que han decimado su población. En lugares como la Amazonia las epidemias todavía golpearon con fuerza durante el siglo XX. Un reciente artículo de Aparecida Vilaça (2020) nos recuerda que cuando los Wari, un grupo indígena en el suroeste de la Amazonía, fueron contactados entre 1956 y 1962, los forasteros trajeron enfermedades, y las epidemias resultantes fueron devastadoras. Gripe, neumonía, parásitos intestinales y una gran variedad de infecciones diezmaron a más de la mitad de la población. Eran enfermedades desconocidas, para las cuales los chamanes no tenían cura. Los wari que sobrevivieron además de ver morir a sus parientes, sufrieron una gran hambruna al ser expulsados de sus tierras de cultivo por propietarios de plantaciones de caucho.

También desde Brasil, Carlos Fausto (2020) escribe sobre la huella que dejó la epidemia de sarampión de 1954 en la memoria de los habitantes del Alto Xingu, sobre como muchos comparan la actual epidemia con aquel trágico episodio, especialmente al recordar a todos aquellos que murieron sin poder ni tan siquiera ser enterrados.

Otro caso amazónico, bien documentado por Philippe Erickson, es el de los matis. Entre los años 1970-1980, tras ser sedentarizados por los blancos, los matis perdieron dos tercios de su población por culpa de varias epidemias. 
Antaño dispersos, aislados y móviles, en los 1980 los matis no eran más de cien y estaban agrupados alrededor de un Posto Indigena de Atração de la FUNAI. Para ese entonces ya se habían hecho dependientes de las medicinas y los bienes manufacturados de los mismos que les habían llevado las enfermedades. La desaparición durante las epidemias de todos los ancianos, y la aparición de la FUNAI conllevaron un debilitamiento de los rituales, las normas tradicionales y la introducción de influencias occidentales. En esta reconstrucción identitaria todo se transformó dando lugar a nuevos equilibrios. Los efectos de las epidemias en las sociedades amazónicas de los 1970, trastocaron el orden establecido, incluso en algunos casos como el de los tapirapés, el chamanismo fue abandonado por ser considerarlo responsable de la hecatombe demográfica (Wagley, 1979; Baldus, 1976: 45).

Aunque en el siglo XX la situación de los pueblos indígenas de Panamá no es equiparable a la de estos pueblos amazónicos, las epidemias no forman parte de un pasado lejano. A día de hoy las comunidades gunas y emberás del oeste de Panamá, todavía recuerdan los devastadores efectos que tuvo un brote de cólera activo en los años 1991-1992. También la tuberculosis sigue siendo una enfermedad con gran afectación en las densamente pobladas islas de Gunayala. Las memorias colectivas entorno a las epidemias pasadas condicionaron la rápida respuesta de las autoridades comarcales y locales de Gunayala. El temor al contagio y a la falta de medicina para remediarlo, llevaron a un rápido cierre de la región y a un repliegue familiar.

El otro factor que determinó esta rápida respuesta está relacionado con el lugar que ocupan las llamadas bonigan (enfermedades, seres patógenos) en el sistema ontólogico guna. Para muchos de los habitantes de Gunayala, las bonigan son concebidas como seres que amenazan constantemente a las personas humanas y pertenecen al mundo no visible (Chapin, 1983). Se trata de seres que no tienen un origen parecido al de los humanos. Al igual que los árboles y las plantas, las bonigana fueron creadas por Baba (Padre creador) y Nana (Madre creadora) independientemente de los humanos y los animales. Son, por lo tanto, seres anti-humanos. Lo que las hace diferentes de seres como los árboles, es que estos fueron creados para hacer posible la vida de los gunas en la tierra, mientras que las bonigana llegaron para acabar con ella. Finalmente, 
un elemento que las diferencia y las hace muy temibles es que con las bonigana la comunicación directa no es posible. Para hacer que se alejen, los nergan (chamanes) deben recurrir a otras entidades no humanas y no siempre logran expulsarlas.

Estos elementos, de carácter histórico y ontológico permiten entender, en parte, porqué la respuesta inicial al coronavirus fue tan contundente en las comunidades gunas de la costa atlántica. A estos elementos de orden simbólico se suma la falta, ya crónica, de equipamiento y personal sanitario en la comarca. Para una población de más de 30.000 personas la región solo cuenta con un pequeño hospital creado por la iglesia bautista norteamericana a mediados del siglo XX en la isla de Ailigandi. Aunque hace décadas que se proyecta la construcción de un hospital o clínica que pueda ofrecer una atención sanitaria más completa, la mayoría de proyectos no han visto la luz o han quedado inconclusos. Un buen ejemplo de ello es la policlínica medio construida, hoy casi en ruinas, en el último tramo de la carretera Llano-Gardi. Con todo, la población de Gunayala es completamente consciente que con la llegada del Covid-19 no cuentan con ninguna Unidad de Cuidados Intensivos (UCIS), y que el centenar que apenas existe en Panamá, le es de muy difícil acceso.

Otro elemento que preocupaba a muchos habitantes de la comarca era la rápida propagación del virus en el caso que llegase algún familiar contagiado. Las condiciones de hacinamiento en las que viven muchas familias aumentan de forma exponencial las probabilidades de contagio local. Aunque durante las últimas décadas los gunas han hecho crecer las islas ganado espacio al mar, el crecimiento de su superficie no ha sido proporcional al de su población, por este motivo la mayoría de unidades domésticas vive en espacios muy reducidos. En algunos casos, una vivienda de $50 \mathrm{~m} 2$ puede albergar a más de 10 personas.

Ante esta situación, el pueblo guna decidió protegerse cerrando su territorio. La consigna "quédate en casa" triunfó tanto en las redes sociales como en las comunidades de la comarca. En muchas islas se izó la bandera roja indicando cuarentena, las familias se encerraron en sus casas, las autoridades locales repartieron turnos para ir a comprar, y muy rápidamente se prohibió cualquier desplazamiento en bote o panga. Solo se permitía tomar el cayuco para ir a las 
fincas o a pescar. El traslado de pasajeros y comuneros, mercancías y víveres por la carretera Llano-Gardi, la principal vía de acceso terrestre a la comarca, se mantuvo abierta, sin alteraciones, hasta el día 16 de marzo, pero a partir del 13 algunas comunidades ya empezaron a emitir comunicados en los que daban a conocer su voluntad de aislamiento. Tal es el caso de las comunidades Nuevo Sasardi y Sasardi Muladup, ambas situadas en la misma isla, que suspendieron reuniones de cualquier tipo y anunciaron que a partir del 16 de marzo no dejarían entrar ni salir a nadie, o el de Uggubseni impidiendo el ingreso de personas provenientes de la ciudad a partir del 15 de marzo o el de Ailigandi prohibiendo la movilidad de comuneros y no residentes desde el día 14.

Hasta el día 16 de marzo no se suspendieron los servicios de transporte de pasajeros de la ciudad hacia la comarca de Gunayala ${ }^{7}$. Los de mercancías siguieron operativos hasta el día 17 de marzo, pero a pesar de ser suspendidos por el Congreso General de Gunayala (CGG), esta misma entidad autorizó una apertura controlada de algunos proveedores registrados por la Secretaría de Transporte del CGG durante los días 24, 25 y 26 de marzo para facilitar el aprovisionamiento de azúcar, arroz, harina, sal, café, aceite, tanques de gas y combustible. Por vía marítima, también se permitió el ingreso de cuatro embarcaciones de carga, previamente autorizadas por el CGG. El acceso se volvió a abrir del 29 de marzo al 9 de abril y en posteriores periodos para ingreso de mercancías de primera necesidad. La entrada de bebidas alcohólicas fue prohibida tanto por las autoridades nacionales como por las comarcales. En todo el país imperó la ley seca hasta que finalizó el estado de emergencia proclamado el 24 de marzo (Decreto Ejecutivo 507).

Por lo que respecta al acceso por vía aérea, todos los vuelos a las comarcas incluida la de Gunayala- fueron suspendidos por la Autoridad Aeronáutica Civil el 17 de marzo. A partir de esa fecha y hasta el 28 de septiembre ${ }^{8}$ solo estuvo permitido volar a los aviones que transportaban ayuda humanitaria. Una curiosa

7 Algunos dules que viven en la ciudad no tuvieron oportunidad de volver a sus comunidades o descartaron hacerlo para evitar la propagación del virus: https://matematicagunaa.wordpress.com/2020/03/26/solidaridad-convivencia-comunitariedadque-es-y-como-se-practica [última consulta, 10-10-2020] 8 Resolución n¹52/DG/DJ/AAC Que reactiva la operación de los vuelos domésticos a partir del 28 de septiembre de 2020 
excepción a esta directriz, fue el sobrevuelo que realizó el domingo de ramos el arzobispo metropolitano con un helicóptero del Servicio Nacional Aeronaval para bendecir Panamá desde el cielo. El avión no entró en el espacio aéreo de la comarca de Gunayala.

Las medidas adoptadas por las autoridades comarcales con el aval del Estado permite pensar la autonomía indígena en Panamá, concretamente en la comarca de Gunayala. Durante esta primera fase de la pandemia el CGG logró controlar los principales accesos terrestres y marítimos a su territorio. Las comunidades también mantuvieron su margen de autonomía, decretando en algunos casos, medidas más restrictivas que las anunciadas por el ente comarcal o el Estado. Con todo, Gunayala fue la última región del país donde aparecieron casos de Covid-19, pero no logró escapar a la entrada del virus. El 26 de marzo se reportó el primer caso, en la comunidad de Assdub ${ }^{9}$. Durante los próximos días se confirmó un caso en Narganá, el de Iguayoliker Ferrer -excacique general-quien fue primero trasladado al hospital de Chepo y luego al Santo Tomás de la ciudad capital. El primer habitante de Gunayala que murió por Covid-19 fue un trabajador, el motorista, del hospital Marvel Iglesias de Ailigandi. Falleció el 5 de abril en un hospital de Panamá. Ese mismo día se informó de dos casos nuevos de Covid-19 en la comunidad de Gardi Sugdub, la que se encuentra delante del principal puerto de entrada a la comarca. Desde ese entonces todas las personas que dieron positivo a los test practicados por los sanitarios de la región fueron aislados en los centros de salud, pero aún y así se produjeron contagios en 13 comunidades ${ }^{10}$.

\section{PENSAR LA AUTONOMÍA INDÍGENA EN TIEMPOS DE EXCEPCIONALIDAD}

Al hacer balance de la gestión de la pandemia por parte del poder central del Estado y las autonomías indígenas durante las primeras semanas que siguieron

9 https://www.midiario.com/nacionales/lo-ultimo-guna-yala-con-primer-caso-positivo-de-covid19/ [última consulta: 8-10-2020]

10 Concretamente se reportaron casos en las comunidades de Gardi Sugdub, Nalunega, Ustupu, Ogobsucum, Puerto Obaldía, Sasardi, Uggubseni, Gardi Dubir, Gardi Yandub, El Porvenir, Wichubwala, Ugguba y Carreto (datos facilitados por Blas López durante el periodo de marzo a octubre de 2020). 
a la proclamación de la situación de pandemia, un primer elemento a tener en cuenta es la cuestión del control territorial. En el caso de la comarca de Gunayala, se hace evidente que los medios -tanto estatales como autonómicoshan sido limitados para controlar el acceso terrestre, al margen del camino LlanoGardi, y marítimo. Sin embargo, en ningún momento se ha negado la capacidad de control de las autoridades comarcales, sino todo lo contrario, cualquier tipo de acción ha sido acordada y realizada junto a éstas. Un ejemplo de ello fue el operativo que el 14 de marzo la dirección Regional de Salud, de Migración, SENAFRONT y el Congreso General de Gunayala llevaron a cabo para aplicar test a extranjeros que se encontraban en yates, veleros y catamaranes en el sector de Maoggi. Por lo que respecta a la policía de fronteras, la SENAFRONT ha acatado las órdenes de las autoridades indígenas ayudando a mantener el checkpoint en Nusagandi (en el límite comarcal) y algunos cercos sanitarios impuestos por las comunidades gunas. Medidas como estas han favorecido la colaboración entre lo comarcal y lo nacional. Han complementado los patrullajes que el CGG y las comunidades realizan en los límites, el monitoreo de las embarcaciones comerciales, pero no han sido suficientes para blindar el territorio: las fugas han sido inevitables. Cuando ya se habían cerrado los accesos, gunas residentes en los centros urbanos del país ingresaron al territorio por tierra, caminando, siguiendo pequeñas trochas a través de la selva (Alemancia, 2020).

$\mathrm{Si}$, por un lado, esta epidemia ha puesto al descubierto una de las principales debilidades del actual modelo económico de muchas comunidades gunas: una creciente dependencia del turismo en detrimento del mantenimiento de actividades agrícolas y cinegéticas, por el otro, esta crisis ha puesto de relieve la precaria situación económica en la que viven miles de familias indígenas migradas a los centros urbanos. La posición socioeconómica que ocupan los indígenas en la gran urbe no les ha permitido sobrevivir en tiempos de pandemia. En algunas poblaciones del extraradio de la ciudad de Panamá con una elevada concentración de población indígena, como Veracruz, se aplicaron estrictos cercos sanitarios (Alemancia, 2020). Estas medidas hicieron crecer el estigma hacia los más desfavorecidos y más todavía sobre los identificados con grupos étnicos. Señalados por vivir en focos de transmisión de la enfermedad, se 
redujeron sus posibilidades de empleo, quedando a merced de la ayuda alimentaria distribuida por el gobierno ${ }^{11}$.

A pesar de las restricciones marcadas por el CGG y las comunidades, la falta de expectativas en la ciudad, el temor al contagio y la incertidumbre que se abrió desde el mes de marzo, llevó a muchos gunas residentes en los centros urbanos a un retorno desesperado a sus comunidades de origen. Esta nueva emergencia obligó a las autoridades comarcales a negociar, tanto con las comunidades como con las agencias gubernamentales, la creación de un llamado corredor humanitario para facilitar el retorno de migrantes con garantías sanitarias ${ }^{12}$. De esta manera, a mediados de agosto, entraron los primeros grupos organizados por el Congreso respetando los protocolos establecidos por las autoridades sanitarias y comunitarias, entre ellos cumplir medidas de prevención, control y cuarentena (14 días de aislamiento antes de mezclarse con el resto de comuneros) ${ }^{13}$. A la hora de planificar estos desplazamientos siempre se tuvo en cuenta la voluntad de las comunidades respecto al retorno de migrantes. En total, durante el periodo comprendido entre el día 18 de agosto hasta el 6 de octubre de 2020 los puertos de entrada a la comarca -Niga Kantule y Dibincontabilizaron 2199 personas que se dirigieron a 48 de las 51 comunidades que integran Gunayala ${ }^{14}$.

Además de regular los flujos migratorios de la ciudad a la comarca, durante la pandemia el Congreso General ha decretado sanciones y restricciones a algunas comunidades de la comarca que no han cumplido con las medidas sanitarias para frenar los contagios por coronavirus. Este ha sido por ejemplo el caso de las comunidades de Mammardub y Urgandi. El mes de mayo el Congreso impuso una cuarentena total a ambas comunidades, suspendiendo el acceso a los puertos para recoger mercancías. La máxima autoridad de la comarca también

11 Durante la crisis sanitaria un tercio de la población del país ha recibido bolsas de comida del programa de emergencia Panamá Solidario (cf. Foyer, 2020).

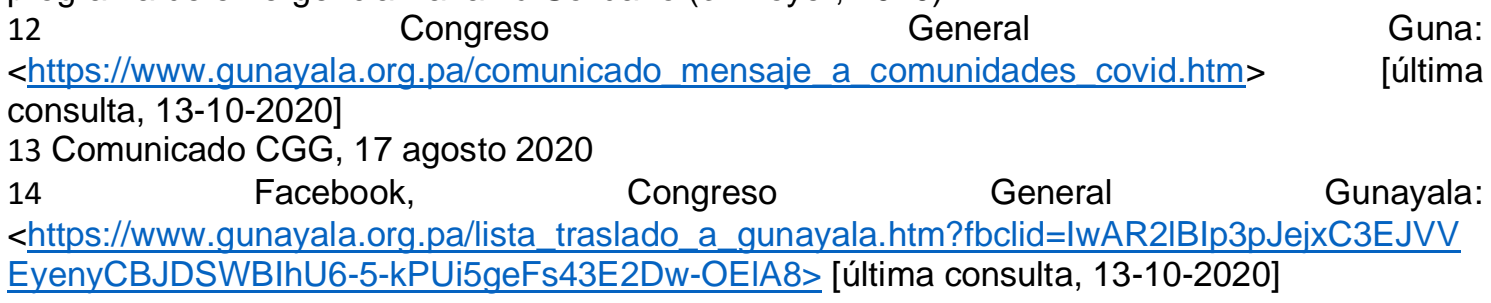


condicionó las futuras autorizaciones de permisos de salida de los comuneros de estas comunidades ${ }^{15}$ y la viabilidad de las actividades turísticas en su área al cumplimiento de las medidas de prevención. Por último como medida de coerción, el Congreso también les señalaba que haría cumplir la ley nacional sobre "Delitos contra la salud pública" vigente en el Código penal que en su articulo 308 según el cual "si alguien intencionadamente propaga una enfermedad peligrosa será sancionado con una pena de prisión de cuatro a seis años. Pero si es una enfermedad contagiosa, como lo puede ser el coronarvirus, la sanción será de diez a quince años de prisión"16.

Este repaso de medidas, acciones y negociaciones nos confirma que en Panamá los pueblos indígenas, al menos los gunas, han podido gestionar la pandemia ejerciendo su autogobierno. Gracias al margen de autonomía de la comarca, Gunayala ha sido una de las zonas del país con menos casos de coronavirus. Las autoridades gunas han tenido el poder de decisión sobre cuándo y cómo decretar medidas de confinamiento, han podido gestionar el flujo de migrantes indígenas de la ciudad a las comunidades y han tenido herramientas para informar a su población. En este sentido es remarcable la labor de la Secretaría de Información y Comunicación del Congreso General y de numerosos comunicadores gunas que han utilizado la radio y las redes sociales ${ }^{17}$ como Facebook o Instagram, para dar a conocer la gravedad de la situación y divulgar medidas de prevención en lengua guna. Desde el 4 de mayo el Congreso General dispone de un espacio radiofónico diario de 10 minutos de duración, en

15 Los habitantes de Gunayala necesitan tramitar un permiso en el seno de su congreso local que es validado en los puntos de salida de la comarca por el personal del Congreso General. Para una reflexión más amplia sobre los permisos de salida cf. Martínez Mauri (2018) 16 Nota CGG, 3 mayo 2020

17 La preocupación por la situación de los pueblos indígenas también ha motivado la articulación de un colectivo de aliados indígenas. Este colectivo ha organizado dos conversatorios retransmitodos a través de Internet para informar de la situación actual. El primero reunió a representantes emberá, wounaan y guna el pasado 15 de julio: Sara Omi, presidenta del Congreso General de Tierras Colectivas del Alto Bayano; Aulina Ismare Chamarra, del Congreso Nacional del Pueblo Wounaan; Reginfo Navas, cacique de la Comarca Guna y Dialis Herman, abogada guna de Nisbundor-Alianza de Mujeres Indígenas <youtube.com/watch? $\mathrm{v}=\mathrm{Ol}-$-llqad97w> [última consulta, 2-10-2020]. El segundo tuvo lugar el 12 de agosto y contó con bribri, naso, buglé y ngäbe. Bellanira Araúz, del Consejo del Pueblo Bribri; Alexis Santana, Rey del Pueblo Naso; Marcelo Guerra, cacique general del Pueblo Buglé; y Elsy Pedrol, presidenta de la Coordinadora General de Mujeres Ngäbe Buglé <youtube.com/watch?v=a1kKiqlumvs\&t=31s> [última consulta, 2-10-2020]. 
la cadena Nacional FM, dedicado a orientar a la población guna en la lucha contra el coronavirus.

Desde mediados de septiembre, después de seis meses, algunas banderas rojas han dejado de ondear en algunas comunidades. A finales de ese mes el Congreso General ha anunciado que se flexibilizarán algunas medidas, entre ellas se permitirá una mayor movilidad interna, se retomarán algunas actividades tradicionales, como los encuentros tradicionales ${ }^{18}$. Estas medidas son adoptadas después que el 25 de agosto de 2020 el gobierno de Panamá aprobara un plan de desconfinamiento progresivo que incluía la reapertura del país al turismo con la reactivación de la Aviación Internacional a partir del 12 de octubre. Pero la flexibilización de las medidas no significa la apertura inmediata de la comarca al turismo nacional o internacional. Aunque para el Congreso y muchas familias gunas las actividades turísticas constituyen su principal fuente de divisas, las autoridades de la comarca han dejado claro que Gunayala decidirá cómo y cuando se abrirá al turismo. Por el momento la Secretaría de Asuntos de Turismo del CGG está actualizando el registro de dueños de cabañas y operadores de turismo en activo para exigirles planes de negocio y protocolos de reapertura. La evolución de la pandemia durante los próximos meses condicionará sin lugar a dudas la relación de los gunas con el mundo. Pero todo parece indicar que seguirán recurriendo a sus instituciones, sus formas organizativas y normas propias para intentar dar respuestas y resolver los problemas que irán apareciendo.

\section{CONCLUSIÓN: LOS LÍMITES DE LAS POLÍTICAS DE RECONOCIMIENTO, EL VALOR DE LA INTERCULTURALIDAD}

La gestión de la pandemia en Gunayala nos muestra que el reconocimiento de los sistemas autonómicos de los pueblos indígenas no se limita a sus procedimientos judiciales, sino que incluye la existencia de sus instituciones, autoridades, y su capacidad de control, creación de normas y sanciones. En el contexto actual, el Estado ha tenido en cuenta el dinamismo, propio de todos los sistemas sociales, y la consecuente actualización de los marcos normativos e 
institucionales indígenas. Seguramente este reconocimiento ha venido propiciado por la falta de medios estatales para incidir en los territorios indígenas, pero concuerda con las recomendaciones y directrices de política de las Naciones Unidas (UN/DESA, 2020). Concretamente con las que recomiendan a los gobiernos reconocer la legitimidad de los representantes de los pueblos indígenas, incluirlos en el diseño de servicios de salud y apoyar a las comunidades indígenas que han impuesto cierres para detener la propagación del Covid-19.

A pesar de que el reconocimiento de los sistemas de autogobierno es real, quedan pendientes muchos otros temas de gran importancia para las sociedades indígenas. Poco se ha hablado de la mala muerte: de la solitud en la que han fallecido muchas personas hospitalizadas por Covid-19, de la desaparición de los rituales funerarios de todos aquellos que han muerto durante los últimos meses, o de la imposibilidad de trasladar los cuerpos de los difuntos a su lugar de origen para recibir sepultura en los cementerios comunitarios. Estos aspectos, difíciles de asimilar en cualquier sociedad humana, son centrales en la experiencia de la vida y la muerte de los gunas. Durante la crisis sanitaria no parecen haber sido tomados en cuenta y en más de una ocasión han servido para estigmatizar nuevamente a los indígenas. El caso de un comunero guna gravemente enfermo de Covid-19 que se negó a ser trasladado a un hospital fuera de la comarca ilustra esta triste realidad. A principios de mayo, al conocerse la muerte del comunero que se negó a ingresar en un hospital citadino, la jefa nacional de epidemiología del Ministerio de Salud, afirmaba ante la prensa que "por un problema de interculturalidad se está teniendo una difícil situación en cuanto al rechazo del traslado de las personas para venir a atenderse de una mejor manera en los hoteles hospital u hospitales. De allí una de las defunciones lamentables"19. En estas declaraciones la epidemióloga deja intuir que la interculturalidad no es un valor, sino un problema que debe ser combatido. De sus palabras emana la idea que la cultura puede ser un obstáculo para la vida. Al cuestionar la decisión del enfermo y de sus familiares por tratarse de un tema

19 "Guna murió de coronavirus por negarse a recibir atención médica", Panamá América, 6-52020. <https://www.panamaamerica.com. pa/sociedad/guna-murio-de-coronavirus-por-negarserecibir-atencion-medica-1162855> [última consulta, 14-10-2020] 
cultural, impone su manera de concebir la vida y el lugar del ser en el cosmos, ambos aspectos de orden cultural. Con todo, este caso nos muestra que si bien las políticas de reconocimiento de la diferencia cultural son validas en algunos contextos, no aplican en otros. Decidir qué tipo de tratamiento es el adecuado, determinar cómo y donde morir, elegir el lugar de sepultura, deberían ser asuntos abordados desde la autonomía indígena al igual que lo son las restricciones de movilidad.

Durante los últimos meses organismos como la OPS/OMS (2020) han señalado que en el contexto de la pandemia los protocolos y lineamientos nacionales deben contemplar un manejo de los cadáveres adecuado, diseñando respuestas específicas, adaptadas a las tradiciones y costumbres de los pueblos indígenas. Sin embargo esta no ha sido la realidad que han conocido muchas familias indígenas que han perdido alguno de sus seres queridos. Es por ello que me parece oportuno concluir recordando que, en estos difíciles momentos, la incorporación de estrategias de comunicación y diálogo intercultural es un reto más para la consolidación de la autonomía indígena en Panamá.

\section{BIBLIOGRAFÍA}

Alemancia, Jesús, "Cosmogonías, pandemia y vida cotidiana de los pueblos indígenas de Panamá”, en: Diálogo político, 26-8-2020: $<$ https://dialogopolitico.org/agenda/cosmogonias-pandemia-y-vida-cotidiana-delos-pueblos-indigenas-de-panama/> [última consulta, 13-10-2020]

Baldus, Herbert, "O xamanismo na aculturaçao de uma tribo tupi do Brasil Central", en Egon Schaden (ed.), Leituras de Etnologia Brasileira, p. 455-462, Companhia Editora Nacional. Sao Paulo, 1976.

Chapin, Mac, Pab Igala. Historias de la Tradición Kuna, Ediciones Abya-Yala. Quito-Equador, 1989.

Chapin, Mac, Curing Among the San Blas Kuna of Panama. PhD dissertation. University of Arizona, 1983.

Crosby, Alfred, "Virgin Soil Epidemics as a Factor in the Aboriginal Depopulation in America”, en The William and Mary Quarterly, 33(2), p. 289-299, 1976. 
Curtice, Kaitlin y Esther, Choo, "Indigenous populations: left behind in the COVID19 response", en Lancet., 395(10239), p. 1753, 2020, <https://www.ncbi.nlm.nih.gov/pmc/articles/PMC7272170/> [última consulta, 1310-2020]

Denevan, William, The Native Population of the Americas in 1492, University of Wisconsin Press. Madison, 1976.

Díaz Polanco, Hector, Indigenous peoples in Latin America: the quest for selfdetermination, Westview Press. Boulder, 1997.

Erikson, Philippe, El sello de los antepasados: marcado del cuerpo y demarcación étnica entre los matis de la Amazonía, Instituto Francés de Estudios Andinos : Abya-Yala. Lima, Quito, 1999.

Fausto, Carlos, "The Measles from the Time of My Grandfather: Amazonian Ethnocide Memories in Times of Covid-19". En: Somatosphere, $<$ http://somatosphere.net/2020/the-measles-from-the-time-of-my-grandfatheramazonian-ethnocide-memories-in-times-of-covid-19.html/> [última consulta: 13-10-2020]

FILAC y FIAY, Los pueblos indígenas ante la pandemia de la covid-19. Tercer informe regional. Comunidades resilientes. Buenas prácticas de los pueblos indígenas ante la pandemia. La Paz, Bolivia, 2020.

Foyer, Jean, "Entre marginalisation et autonomie : le confinement des Amérindiens au Panama". COVIDAM : la Covid-19 dans les Amériques. Blog réalisé en partenariat entre Institut des Amériques et iGLOBES, 2020, $<$ https://covidam.institutdesameriques.fr/entre-marginalisation-et-autonomie-leconfinement-des-amerindiens-au-panama/> [última consulta: 10-12-2020]

González, Miguel, “Autonomías territoriales indígenas y regímenes autonómicos (desde el Estado) en América", en: Miguel González, Araceli Burguete y Pablo Ortiz (Coords.) La autonomía a debate Autogobierno indígena y Estado plurinacional en América Latina. p. 35-63. Ed. Abya Yala. Quito, 2010. 
Herlihy, Peter H, "La revolución silenciosa de Panamá: las tierras de comarca y los derechos indígenas", en Mesoamerica, 29, p. 77-93, 1995.

Martínez Mauri, Mònica, La autonomía indígena en Panamá: la experiencia del pueblo kuna (siglos XVI-XXI). SENACYT, Editorial Abya Yala. Quito, Ecuador, 2011.

Martínez Mauri, Mònica “¿Por qué pagar por entrar a Gunayala? Movilidad turística, soberanía y pueblos indígenas en Panamá”, en: Norois, 247, p. 63-76, 2018.

OPS-OMS, Alerta Epidemiológica COVID-19 en pueblos indígenas en las Américas. 15/07/2020. <https://www.paho.org/es/documentos/alertaepidemiologica-covid-19-pueblos-indigenas-americas-15-julio-2020> [última consulta: $10-12-2020]$

UN/DESA, "The Impact of COVID-19 on Indigenous Peoples", Policy Brief \#70: 8/5/2020, < <https://www.un.org/development/desa/dpad/publication/un-desapolicy-brief-70-the-impact-of-covid-19-on-indigenous-peoples/> [última consulta, 14-10-2020]

Vilaça, Aparecida, "The Twin Threat Facing Indigenous Peoples." Anthropology News website, 17-4-2020.

Wagley, Charles, Welcome of tears, Oxford University Press. New York, 1979.

Wickstrom, Stefanie, "The politics of development in Indigenous Panama", en Latin American Perspectives, 131, 30 (4), p. 43-68, 2003. 